Population Study

Oral

Abstract ID: 8

\title{
10 years review of endowment fund for research in IIUM Kuantan
}

\author{
Nazri Mohd Yusof ${ }^{\mathrm{a}} \mid$ Syazwin Syafira Ahmad ${ }^{\mathrm{a}} \mid$ Khairani Idah Mokhtar $^{\mathrm{b}} \mid$ Ailin Razali $^{\mathrm{a}}$ \\ ${ }^{a}$ Kulliyyah of Medicine, International Islamic University Malaysia \\ ${ }^{b}$ Kulliyyah of Dentistry, International Islamic University Malaysia
}

Introduction: IIUM Research Endowment Fund was initiated to encourage research activities, but was withdrawn in 2015 due to financial constraint. The discontinuity was additionally justified as Endowment Funds being an internal fund, does not contribute to MyRA, an instrument used to gauge research activities in Malaysian Universities. It is divided into Endowment A (Non-S\&T) and B (S\&T) which funds RM5,000.00 and RM20,000.00 accordingly. This study aims to analyze the output of IIUM Kuantan lecturers from the fund from 20052015. Methods: Data were obtained from IIUM Kuantan Research Management Center filing system, which include End of Project Forms and Research Reports among others. The outcome measured includes publication, human capital and seminar presentation. Each outcome was given scores to indicate its importance. Results: A total number of 349 grants, which consisted of 117 grants for Endowment A (RM585,000) and 232 grants for Endowment B (RM4,640,000) were approved since 2006 until 2015. The total amount of grant given was RM5,225,000. Endowment A and B produced 76 and 242 publications, 34 and 121 students' project and 74 and 299 conference presentations accordingly. Endowment A and B utilized RM2839.81 and RM10,108.93 for 1 score accordingly. Conclusions: Although Endowment Grants were not considered in MyRA markings for research grants received, it has contributed significantly to other MyRA scores such as publication, presentation and students' development with a relatively small amount of money.

KEYWORDS: Research Funding, Outcome assessment 